\title{
The Role of Faculty Member in Jordanian Universities in Protecting Students from Cultural Pollution as Perceived by Students
}

\author{
Fadi Soud Samawi ${ }^{1, *}$, Natheer Sihan Abu Nair ${ }^{2}$ \\ ${ }^{1}$ Department of Psychology and Special Education, Princess Alia University College, Al- Balqa Applied University, Jordan \\ ${ }^{2}$ Educational Foundation, Al-Balqa Applied University, Princess Rahma University College, Jordan
}

Received July 21, 2020; Revised September 14, 2020; Accepted September 29, 2020

\section{Cite This Paper in the following Citation Styles}

(a): [1] Fadi Soud Samawi, Natheer Sihan Abu Nair, "The Role of Faculty Member in Jordanian Universities in Protecting Students from Cultural Pollution as Perceived by Students," Universal Journal of Educational Research, Vol. 8, No. 11B, pp. 5869 - 5879, 2020. DOI: 10.13189/ujer.2020.082220.

(b): Fadi Soud Samawi, Natheer Sihan Abu Nair (2020). The Role of Faculty Member in Jordanian Universities in Protecting Students from Cultural Pollution as Perceived by Students. Universal Journal of Educational Research, 8(11B), 5869 - 5879. DOI: 10.13189/ujer.2020.082220.

Copyright $\mathrm{C} 2020$ by authors, all rights reserved. Authors agree that this article remains permanently open access under the terms of the Creative Commons Attribution License 4.0 International License

\begin{abstract}
The study aimed to identify the role of the faculty member in Jordanian universities in protecting their students from cultural pollution from the students' point of view, and whether there is a difference according to the type of university, major, and academic year. To achieve the goals of the study, a scale has been developed that measures the role of the faculty member in protecting his students from cultural pollution, and it was randomly distributed to 2400 male and female students from public and private universities. The results indicated that the role of the faculty member was high in protecting his students from cultural pollution, and that there are differences in the role of the faculty member in protecting students from cultural pollution attributed to the gender variable and in favor of males, and there are no differences in the specialty and year of study, and the study recommends educating male and female students about the importance of the role of the faculty member in protecting them from cultural pollution. The importance of the study lies in providing researchers and Arab libraries with an expanded theoretical framework on the phenomenon of cultural pollution, the results of the current study also benefit the officials in the Jordanian higher education institutions by setting out educational and guidance programs for male and female students about the seriousness of this phenomenon.
\end{abstract}

Keywords Cultural Pollution, Faculty Members,
Students' Point of View, Public Universities, Private Universities

\section{Introduction}

Each society is characterized by a cultural identity that distinguishes it from other societies and shows its personality, and this society seeks through its educational institutions to instill and deepen it in the minds and souls of its children through education and upbringing. Culture in this context goes to concepts and knowledge that represent the identity of society, but these concepts and knowledge may be exposed to some foreign pollutants that can cause the problem of cultural pollution, especially among young people [1].

Liu [2] defines cultural pollution as "some manifestation of the youth's influence on Western culture, which contradicts the values and principles of Arab societies, and this appears in the ideas and beliefs held by young people, in their general behaviors and general appearance."

In addition, cultural pollution as "that flow of culture from dominant cultures to less powerful cultures; it is a kind of cultural flow that contradicts the ideas, principles, and behavior of its members [3].

It is believed that cultural pollution is one of the most 
dangerous types of pollution that threatens young people, especially university youth at the present time, and this kind of pollution rapes souls and pulls them from their roots. So that it becomes an accumulated reality and a serious problem that threatens the whole society [4].

Guo [5] notes that cultural pollution among university youth is clearly spreading due to the currents and variables that young people are exposed to, and this is evident by the ideas they embrace and defend, where the manifestations of this pollution are embodied in their behavior and general appearance, and in customs and traditions, and this gives cause for concern and stimulates the mind to address this phenomenon from its roots, and the danger and impact of cultural pollution on youth and society appears through the distortion of local culture, and limit its ability to play its role in the overall development and human-building processes enabling him/her to deal with the data of the times and the challenges of the future [4].

There are many aspects of cultural pollution that negatively affect the thinking and behavior of young people. Among these are what Sukran referred to, namely: Going towards the downsides and dangers of postmodern culture, and the principles that underlie it and advocate it, these include breaking the foundations, ideals and values of youth, rejecting the usual societal references, violating the social contexts used, the absence of scientific culture and the spread of myth culture [1].

The faculty member plays a very important role in shaping cultural identity and in facing cultural and intellectual risks, rather, it has become in our times one of the most important factors affecting the change and development of societies, it is he who creates its present and charts its future, as he constitutes the intellectual and scientific basis for human societies. And the preparation of human cadres at all levels, in addition to expanding the horizons of human knowledge, through multiple functions which include: Education, Public Service, and Scientific Research [6].

Based on the importance of education and the role of university professors in developing their performance and the performance of students to be the leaders of tomorrow to follow the developments of the present era with its recent developments, and its successive scientific and technological revolutions in the period of transformation and change that the nation is experiencing now, education is currently facing unparalleled challenges worldwide as a result of its progress towards a knowledge-based society and the acquisition, modernization and use of knowledge, hence the role of the university professor in facing these challenges. In fact, the challenges faced by education at the present time are huge challenges related to the pattern of career, and it requires us to change at the heart of our educational structures and in the nature of the roles assigned to learners to exercise their required roles more effectively [7].

Al-Khawaldeh [8] believes that the role of the faculty member is to create the appropriate educational environment, that encourages students to acquire cultural values, values of respect and democracy, and therefore it is the responsibility to provide students with the correct values such as values of loyalty, affiliation, promoting the principle of non-violence, deviation, and awareness and exercise of rights.

In this context, several studies were conducted that dealt with the topic from various aspects. Abu Daf and Al-Agha studied the level of cultural pollution among young people in Palestinian society from the viewpoint of faculty members, and the most important causes of cultural pollution among university students, and a questionnaire has been applied to measure cultural pollution consisting of 41 statements on a sample of 129 male and female students, the results of the study showed that the percentage of cultural pollution among young people in Palestinian society was $63.15 \%$. The results indicated that there are statistically significant differences in the teaching staff's assessment of the level of cultural pollution attributed to the gender variable in favor of females in the field of general appearance, while there were no differences in the field of beliefs and ideas, the field of behavior, and the presence of statistically significant differences attributable to the college variable in favor of human colleges, while there were no differences due to (the place of residence) variable [9].

Yeh, Carter \& Pieterse conducted a study in the United States of America aimed at revealing the relationship between cultural values and racial identity of Asian American students. The sample of the study consisted of 122 students of Asian origin their ages ranged from 17 to 44 years ( 78 females, 44 males) who responded to the scale of attitudes toward ethnic identity (UREIAS)) consisting of 43 paragraphs on beliefs and subjective attitudes towards ethnicity, the values system questionnaire (ISU) consisting of 40 paragraphs distributed on the dimensions: goodness values, mixed values, evil values, submission, consistency, present, future, existence, proof of existence, work, and ethnic group values. Descriptive statistics and stability coefficients were used to reach the results of the study and the results of the study showed that the students' representation of values is closely related to ethnic identity, however, coexistence has led to a mixed value system that unites the Asian side and the East side. The study showed that there are statistically significant differences between males and females in the representation of positive values such as goodness, consistency, presence and proof of existence and the absence of differences in negative values such as evil attributed to the gender variable [10].

The Doghurty Study aimed to identify how to produce difference and cultural similarity in unlimited (global) education that is made in designing communication and Internet inputs; it also aims to know the cultural policy in education that has no borders. The researcher used the ethnographic approach, where he was observing and recording the entries through the websites' unit. Through interviews and dialogues with the lecturers, and electronic 
interviews with students, the study found that the interventions formed a context panel for changing cultural processes from globalization and the educational market, where knowledge is a work. The educational and cultural fields demonstrated the complexities of controlling culture, which live in times of globalization. The analysis also showed the cultural difference between students, which results in a systematic evaluation of a series of educational problems in the case of this study [11].

As for Geozek's study, it aimed to identify the role of faculty in transferring national culture in the classroom, the researchers used the ethnographic research method that was carried out in high schools on the French island of Martinique, and he conducted semi-structured and formal interviews with faculty members, school directors, regional policymakers, archiving research, and exploring ways to shape the national identity within schools. The study found that teachers are concerned with national and regional identity as they strive to reinforce this identity and ethnographic research has helped them define identity discussions and education. And the necessity of providing valuable information for teachers on how to enhance the national identity as reported by the Ministry of Education in Paris [12].

A study conducted by Lam in Vietnam aimed at knowing the role of a faculty member in facing cultural globalization, and its impact on national education policies. The qualitative approach was followed through interviews with a sample of 30 faculty members and 150 students from the University of Bedaouji, the study showed the weak role of the faculty member in facing cultural globalization, and that cultural globalization has a significant negative impact on the national education policies in the country [13].

Al-Ubaidi conducted a study in Iraq aimed at identifying cultural pollution among university students, and their family climate, and the relationship between them, the study sample consisted of 600 male and female students who responded to a questionnaire prepared for the purposes of the study, the study found that students have a high level of cultural pollution, and that the family climate in which they live is not normal, and the absence of statistically significant differences in the level of cultural pollution among students due to the variable of specialization, and the presence of a correlation between cultural pollution and the family climate [14].

As for the Qaisi study, the study aimed to identify the level of academic and health problems, which Tafila Technical University students suffer from, and the study sample consisted of 300 male and female students, they were chosen in a randomized, stratified manner, and the results showed that the areas of health problems are the most common problems experienced by students. It is followed by financial problems, then academic problems. The results also indicated that the most prevalent problems among university students are: having more than one exam per day, the high prices of books, the lack of hygiene in health facilities at the university, and the lack of specialized doctors in the clinic, and the insufficiency of medicines in the clinic. The results of the study showed that there are no statistically significant differences in the areas of problems facing university students due to gender or the interaction between gender and college [15].

The Arhum study revealed the impact of media globalization through direct satellite broadcasting on the cultural identity in Libyan society for satellite channels and the most important channels, which reflects on the consistency of values within society, by identifying the motives for the Libyan public's use of the favorite satellite channels, this study relied on the social survey method of the sample due to the difficulty of a comprehensive count of university students, the researcher also relied on an interview form to obtain field data on youth related to behavior, clothing and personal appearance. This study found that satellite TV uses indirect means, including films and series that include persuasive art and methods that are presented in bright and attractive templates. It arrives indirectly, and may therefore affect changing attitudes, ideas, and beliefs [16].

Through the foregoing studies, the seriousness of the phenomenon of cultural pollution has been observed. The studies highlighted the need to conduct more research and studies to investigate the factors influencing the role of the educational issue in general and the faculty member in particular in facing the manifestations and effects of this phenomenon, through the scientific and practical role he plays, through which the students can confront this phenomenon.

The current study has benefited from seeing this many studies in deepening awareness of this phenomenon, preparing for its tools, discussing the results, and then providing the appropriate recommendations.

\section{Theoretical Background}

A common trait influencing identity is culture. Identities are socially constructed through a cultural lens. We identify with our initial cultural in-group as a function of enculturation, and later expand to other cultural groups or social institutions as a product of interaction [17]. Consequently, Society decides which identity is socially appropriate. In a world where multicultural interactions are increasingly inescapable, identity must be understood [18].

Culture is defined as a transmitted system of symbols, meanings and norms from a historical chronology [19]. Culture is systemic, the system is made up of patterned symbols such as verbal messages, nonverbal cues, emblems and icons, as well as their interpretations or their assigned meaning. Culture is not only speaking a language and using symbols, but interpreting these symbols consistently [20].

The youth stage is considered one of the most important stages of the human life and one of the most vital, active and complex, because it comes as part of the adolescence 
stage, which some scholars have described as the stage of crisis, the stage of identity formation, the stage of character formation and independence [21], and what accompanies this stage not only that, but the youth stage is considered the stage of the beginning of independence from the family, it is the stage of work, marriage and reproduction that affect the youth and those around them, such as family and society. And production, as their bodies and minds begin to complete and their idiosyncrasies, interests and preparations begin to emerge and develop, and society depends a lot on young people as they are the pillars of the present and the hope of the future, as it depends on them to build themselves, protect their families and society, and defend their homelands and their security [22].

Youth stage is characterized by a dynamic and rapid character, because it is the preparation stage and the stage of taking an active role in building society, for it has a sensitivity to everything new and they are in a constant desire for change. Sources such as the multicultural and advanced media have changed the personality of young people and their balance [21], and generated many contradictions in which they live and interact with them on a daily basis, and have eliminated the influence of the factors that make up the personality, which is parental social upbringing, in order to replace them with upbringing stemming from alternatives. This resulted in the value struggle between youth and the behaviors stemming from other cultures intertwined with the culture of the society, as well as affected by the current position of youth through which youth establish their relationship with society [22].

The mass media has become highly productive, fast-moving, powerful, and widespread in time and place, which has made a major impact on raising and educating members of society and influencing their behavior [23]. Based on the foregoing, this study focuses on what may be going on in the minds of young people in the Jordanian universities about one of the most dangerous and important topics of the era, which is their culture in light of the unlimited openness represented by the internet and satellite channels. This study investigates the roles of the faculty members in protecting university students from cultural pollution.

\section{The Study Problem and its Questions}

University young people currently suffer from a lot of intellectual currents that have had a great impact on their culture, and it led them to fall into a culture that is alien to their customs and traditions with all its intellectual, behavioral and personal manifestations, as a result, cultural pollution was common among young people [14].

The role of university education and specifically the faculty member in facing this danger of cultural pollution is highlighted, as it is able to provide the university youth with the skills and knowledge that enables the student to distinguish between what is valid and what is not valid from these intellectual and cultural currents [12, 15].

Through the researchers' experience of the reality of university students - as the researcher works in university education - they noticed that there are many aspects of cultural pollution among young people, where these manifestations start from ideas and beliefs, extend to general behavior, and end with the outward appearance of the young person, accordingly, the researchers decided to carry out this study to identify the level of cultural pollution among a sample of university students, and the role of the faculty member in confronting it, as a prelude to providing appropriate recommendations, especially in the absence of local studies dealing with this topic.

\section{Specifically, the Present Study Seeks to Answer the Following Questions}

1. What is the role of a faculty member in facing cultural pollution among students from the point of view of university students?

2. Are there statistically significant differences in the study sample for the role of the faculty member in facing cultural pollution among students from the viewpoint of university students due to the variables of gender, specialization, and school stage?

\section{Objectives of the Study}

The present study aims to learn about the concept of cultural pollution and the role of the faculty member in facing cultural pollution among students from the perspective of university students, and whether there are statistically significant differences in the perceptions of the study sample for the role of the faculty member in facing cultural pollution among students from the viewpoint of university students due to gender, specialization, and academic year.

\section{The Importance of the Study}

\section{A. Theoretical importance}

The importance of the study lies in providing researchers and Arab libraries with an expanded theoretical framework on the phenomenon of cultural pollution, in particular, studies in this field in the Arab environment in general and the local environment in particular are still few.

The study deals with the subject of cultural pollution among university students, especially since they are at a higher level of study, which will take them out to the labor market. To society, and therefore there is a need to identify the level of cultural pollution they have in the light of gender, student specialization, and university year.

\section{B. Applied importance}

- The results of the current study benefit the officials in the Jordanian higher education institutions by setting out educational and guidance programs for male and 
female students about the seriousness of this phenomenon.

- $\quad$ The results of the study may be useful in applying strategies to confront the phenomenon of cultural pollution to reduce its impact and its seriousness on the intellectual and behavioral situation of students.

- The present study contributes to introducing researchers to more measures on the phenomenon of cultural pollution, and it can be used for future research.

\section{Conceptual and Procedural Definitions}

Cultural pollution: reference [9] defines the cultural pollution as "some manifestations of youth being affected by the Western culture, which contradicts the values and principles of Arab societies, and it appears clear through ideas, beliefs, behaviors and the general appearance of youth.

Procedurally, it is the degree to which Jordanian university youth are affected by Western culture. It is also reflected in their response to the study tool in the areas of beliefs and ideas, behavior and general appearance.

Faculty member: The researchers define it procedurally as a university professor who holds a $\mathrm{PhD}$, and he is the one who performs this function and who works to spread knowledge through the process of teaching and producing knowledge through what he offers from researches and studies. He also has a distinguished and prestigious place by members of society.

\section{Study Limits and its Limitations}

Spatial limits: Jordanian public and private universities

Time limits: for the academic year 2018/2019

Human limits: Students of Jordanian public and private universities.

\section{Methodology}

\section{The study design}

The current study used the descriptive analytical way

\section{The Study Population and its Sample}

The study population consisted of all undergraduate students in Jordanian public and private universities and registered in the academic year 2018/2019, and their number is 230000 male and female students, according to the data issued by the Ministry of Higher Education. The sample of the study consisted of 2400 male and female students who were chosen using the simple random sample method. Table (1) shows the distribution of the study sample according to its variables:
Table 1. Distribution of the study sample

\begin{tabular}{cccc}
\hline \multicolumn{2}{c}{ Variable } & Frequency & Percentage \\
\hline \multirow{2}{*}{ University } & Governmental & 1436 & $60 \%$ \\
\cline { 2 - 4 } & Private & 964 & $40 \%$ \\
\hline \multirow{2}{*}{ Gender } & Male & 1289 & $54 \%$ \\
\cline { 2 - 4 } & Female & 1102 & $46 \%$ \\
\hline \multirow{2}{*}{ Specialization } & Scientific & 1090 & $45 \%$ \\
\cline { 2 - 4 } & Humane & 1310 & $55 \%$ \\
\hline \multirow{2}{*}{$\begin{array}{c}\text { Academic } \\
\text { level }\end{array}$} & first & 717 & $30 \%$ \\
\cline { 2 - 4 } & Second & 596 & $25 \%$ \\
\cline { 2 - 4 } & Third & 559 & $23 \%$ \\
\hline & Fourth & 528 & $22 \%$ \\
\hline
\end{tabular}

\section{The Study Tool}

To measure cultural pollution among students, a scale was developed based on theoretical literature and previous studies, including a study [14], [3], [12]. The scale of 30 statements is divided into three domains, they are: self-management, beliefs and ideas and it consists of 10 statements, and the domain of behavior and consists of 10 statements, and the field of general appearance and consists of 10 statements.

\section{Development of the instrument}

\section{Validity of the study tool}

First: Validity of the statements related to the study variables:

It aims to verify the accuracy of the study scale and be accurate in obtaining data. The scale was subjected to a set of tests through the validity and reliability test.

Second: The validity of the study tool: The apparent validity (validity of the jury members)

The study relied to verify the statements of the questionnaire and its limits on the results of the jury members (validity of the jury members) and includes apparent validity, validity of the content, by presenting it to a group of 8 specialized and experts with academic specialization, to define the related concepts and variables, and formulate the statements indicating them accurately, and the observations received from the jury members were taken into account and unloaded, where some of the statements were corrected and others were added, and some of the statements were merged until the extent of the content of the phrases related to the subject of the study became of high strength and in a language understood and clear by the respondents.

\section{Construction validity}

The verification was achieved by calculating correlation coefficients between domains and the overall score of the scale as shown in Table (2) on a sample of 150 male and female students from outside the study sample. 
Table 2. Correlation coefficients between statements, the overall score of the scale and the domain to which it belongs

\begin{tabular}{|c|c|c|c|c|c|c|c|c|}
\hline $\begin{array}{c}\text { Item } \\
\text { number }\end{array}$ & $\begin{array}{c}\text { Correlation } \\
\text { with the } \\
\text { domain }\end{array}$ & $\begin{array}{l}\text { Correlation } \\
\text { with the tool }\end{array}$ & Item number & $\begin{array}{l}\text { correlation } \\
\text { with the } \\
\text { domain }\end{array}$ & $\begin{array}{c}\text { Correlation } \\
\text { with the } \\
\text { tool }\end{array}$ & $\begin{array}{c}\text { Item } \\
\text { number }\end{array}$ & $\begin{array}{c}\text { Correlation } \\
\text { with the } \\
\text { domain }\end{array}$ & $\begin{array}{c}\text { Correlation } \\
\text { with the } \\
\text { tool }\end{array}$ \\
\hline 1 & $.6030^{* *}$ & $.8210 * *$ & 11 & $.4870 * *$ & $.4730^{* *}$ & 21 & $* 0.400$ & $.3590^{*}$ \\
\hline 2 & $.4800 *$ & $.4520 * *$ & 12 & $.4230 * *$ & $.3430 * *$ & 22 & $* 0.539$ & $.5530^{*}$ \\
\hline 3 & $.5680^{*}$ & $0.372 *$ & 13 & $.6220 * *$ & $.4780^{* *}$ & 23 & $* * 0.451$ & $* * 0.775$ \\
\hline 4 & $.3970^{*}$ & $* * 0.600$ & 14 & $.3720 * *$ & $.4200 * *$ & 24 & $* * 0.732$ & $.3920^{*}$ \\
\hline 5 & $.6800 * *$ & $.5190^{*}$ & 15 & $.6210^{* *}$ & $.5430 * *$ & 25 & $* * 0.776$ & $.5480 *$ \\
\hline 6 & $.3800^{*}$ & $* * 0.724$ & 16 & $.7220 * *$ & $.6510 * *$ & 26 & $* * 0.658$ & $.6210^{* *}$ \\
\hline 7 & $.5670^{* *}$ & $.4350 * *$ & 17 & $.4760^{*}$ & $.5560^{*}$ & 27 & $* * 0.359$ & $.4410 * *$ \\
\hline 8 & $.5520 * *$ & $.8320 * *$ & 18 & $.5400 * *$ & $.6780^{*}$ & 28 & $* 0.525$ & $.4760^{*}$ \\
\hline 9 & $.4950^{*}$ & $.3410 * *$ & 19 & $.5870 * *$ & $.4570^{* *}$ & 29 & $* * 0.745$ & $.3210^{*}$ \\
\hline 10 & $.8550^{* *}$ & $0.392 *$ & 20 & $.7570^{* *}$ & $.4550^{* *}$ & 30 & $* * 0.574$ & $.4450 *$ \\
\hline
\end{tabular}

* Statistical function at the level of significance $(0.05) . *$ Statistically significant at the level of significance $(0.01)$.

\section{The reliability of the study tool}

The reliability coefficient indicates the quality of the questionnaire statements and their internal consistency, and the extent of their consistency in measuring dimensions on a sample of 150 male and female students from outside the study sample.

It was reached by the internal consistency coefficient of Cronbach Alpha [1], and Table (3) illustrates this:

Table 3. The values of the coherence factor for the internal dimensions of cultural pollution

\begin{tabular}{cccc}
\hline Dimension & M & SD & $\begin{array}{c}\text { Cronbach } \\
\text { Alpha }\end{array}$ \\
\hline Beliefs and ideas & 4.13 & .620 & .924 \\
\hline Behavior & 3.90 & .687 & .901 \\
\hline General Appearance & 4.24 & .697 & .932 \\
\hline Total cultural pollution & 3.96 & 586 & .952 \\
\hline
\end{tabular}

Table (3) shows that the Cronbach alpha values for all sub-domains of the study ranged between $.901-.924$, and the total .952 , and this indicates the existence of internal consistency for the statements of the questionnaire and their domains, according to [1], as it is considered the minimum acceptable reliability .700 .

\section{The suitability of the study model for the statistical methods used}

Multiple linear regression test

This phenomenon indicates an almost complete linear correlation between two or more domains, which amplifies the value of the $\mathrm{R}^{2}$ coefficient and makes it greater than its actual value; therefore, the Pearson correlation coefficient and the coefficient of the contrast amplification coefficient were calculated at each variable according to the hypothesis being tested. Table 4 shows that:
Table 4. Correlation coefficients for the dimensions of cultural pollution

\begin{tabular}{cccc}
\hline $\begin{array}{c}\text { Dimensions of } \\
\text { cultural pollution }\end{array}$ & $\begin{array}{c}\text { Beliefs and } \\
\text { ideas }\end{array}$ & Behavior & $\begin{array}{c}\text { General } \\
\text { Appearance }\end{array}$ \\
\hline Beliefs and ideas & 1.000 & & \\
\hline Behavior & $.755^{*}$ & 1.000 & \\
\hline $\begin{array}{c}\text { General } \\
\text { Appearance }\end{array}$ & $.476^{* *}$ & $.675^{* *}$ & 1.000 \\
\hline
\end{tabular}

Table (4) indicates that the correlation coefficients for domains ranged between the domains of behavior, beliefs and ideas, and its value .755 , where the value of the correlation coefficient was not exceeded .80 , an indication of the absence of the problem of multiple high linear correlation.

\section{Variance inflation factor (VIF) test}

To ensure that there is no near-perfect linear correlation between two or more dimensions, this test is carried out by extracting the value of the variance inflation factor at each variable according to the question being answered, and the results were as follows:

Table 5. Results of the multiple correlation test between the dimensions of cultural pollution

\begin{tabular}{ccc}
\hline $\begin{array}{c}\text { Dimensions of } \\
\text { cultural pollution }\end{array}$ & $\begin{array}{c}\text { Allowed variance } \\
\text { Tolerance }\end{array}$ & $\begin{array}{c}\text { Variance of } \\
\text { Inflation Factor } \\
\text { (VIF) }\end{array}$ \\
\hline Beliefs and ideas & .329 & 3.048 \\
Behavior & .237 & 4.254 \\
General Appearance & .285 & 3.472 \\
\hline
\end{tabular}

Table (5) shows that the VIF values were all greater than 1 and less than 10, they ranged between 3.048 and 4.254 , and the Tolerance allowed value was between $0.1 .-1$, and it ranged between $0.237-0.329$, and this indicates that there is no problem of multiple linear correlation between all dimensions of the study. 


\section{Scale Scoring}

The scale consists of 30 statements, the respondent places an (X) in front of each statement to show the extent to which the content of the statement matches with what suits it, it is a type of self-report that the student answers in the light of the five-step scale (very high: 5 high: 4, medium: 3, low: two, very low: one). To calculate the averages of the study sample, the following equation was used to extract the range for each of the three levels: (the higher category - the lower category) / 3; that is, 5-1 divided by 3 is equal to 1.33 , and therefore: from $1-2.33$ degrees low, from 2.34-3.67 degrees medium, and from 3-5.68 degrees high.

\section{The Results of the Study and Its Discussion}

The first question: What is the role of a faculty member in Jordanian universities in protecting students from cultural pollution from the students' point of view?

To answer this question, mathematical averages, standard deviations, rank, and the relative importance of the responses of the study sample individuals were extracted. On the paragraphs on the dimensions of cultural pollution according to the following:

\section{First: ideas and beliefs}

It is clear from Table (6) that all paragraphs related to the domain of beliefs and ideas got a high degree through the answers of the members of the study sample, So that statement 2, which states: "The faculty member reinforces the concept that religion is not against civilization" has the highest arithmetic average of 4.53 and with a high degree, paragraph (6), which states: "The faculty member directs me to respect the girl, regardless of the nature of her clothes," got the lowest average score of 4.03 and also with a high degree, whereas, the overall mean for the domain of beliefs and ideas was 4.24, with an overall high degree, and a total standard deviation .697. Perhaps this result is due to the role of the intellectual faculty member. The faculty member is not a carrier of knowledge but rather an individual who is able to develop values, and amending the ideas and beliefs of the student, especially as this includes protecting the student from cultural and intellectual pollution and protecting him from intellectual and behavioral deviation. This is consistent with what Hudson study [6], which indicated that the faculty member plays a very important role in shaping cultural identity and in facing cultural and intellectual risks, rather, it has become in our times one of the most important factors affecting the change and development of societies. But also, he became among the most vital factors in developing societies as he constitutes the intellectual and scientific basis for human societies. This finding was consistent with the result of the Geozek Study [12], which emphasized the importance of the teacher's role in promoting intellectual values and the national identity of the student, protecting him from cultural pollution and its deviations.

Table 6. Arithmetic Averages, Standard Deviations, and Ranks for Paragraphs of Dimensions of Beliefs and Ideas

\begin{tabular}{|c|c|c|c|c|c|}
\hline Item number & Beliefs and ideas & M & SD & Rank & $\begin{array}{c}\text { Relative } \\
\text { importance }\end{array}$ \\
\hline 1 & $\begin{array}{l}\text { The faculty member directs me that religion } \\
\text { is not limited to worship rituals }\end{array}$ & .694 & 4.37 & 3 & High \\
\hline 2 & $\begin{array}{l}\text { The faculty member reinforces the concept } \\
\text { that religion is not against civilization }\end{array}$ & .645 & 4.53 & 1 & High \\
\hline 3 & $\begin{array}{l}\text { The faculty member explains the relationship } \\
\text { between correct belief and the associated } \\
\text { behavior }\end{array}$ & .786 & 4.21 & 7 & High \\
\hline 4 & $\begin{array}{l}\text { The faculty member adopts the idea of } \\
\text { complete equality between male and female }\end{array}$ & .823 & 4.06 & 8 & High \\
\hline 5 & $\begin{array}{l}\text { The faculty member respects the student's } \\
\text { beliefs and ideas }\end{array}$ & .837 & 4.20 & 4 & High \\
\hline 6 & $\begin{array}{l}\text { The faculty directs me to respect the girl } \\
\text { regardless of the nature of her clothes }\end{array}$ & .903 & 4.03 & 10 & High \\
\hline 7 & $\begin{array}{l}\text { The faculty member considers the student's } \\
\text { success an indication of his goodness, } \\
\text { regardless of his thoughts }\end{array}$ & .571 & 4.41 & 2 & High \\
\hline 8 & $\begin{array}{l}\text { The faculty member respects the student's } \\
\text { personal freedom }\end{array}$ & .690 & 4.24 & 5 & High \\
\hline 9 & $\begin{array}{l}\text { The faculty member believes in the idea of } \\
\text { mixing in the university }\end{array}$ & .710 & 4.22 & 6 & High \\
\hline 10 & $\begin{array}{l}\text { The faculty member accepts any belief or } \\
\text { idea that conflicts with his ideas }\end{array}$ & .785 & 4.04 & 9 & High \\
\hline & & & 4.24 & .697 & High \\
\hline
\end{tabular}




\section{Second: Behavior}

It is clear from Table (7) that all items related to the domain of behavior obtained a high degree through the answers of the members of the study sample, so that paragraph 7, which states: "The faculty member encourages the exchange of text messages between students" at the highest arithmetic average of 4.31 and with a high degree, Paragraph 6, which states: "The faculty member is concerned with the behavior issued by the student," has got the lowest mean score of 4.29 and also with a high degree, whereas, the total arithmetic mean for the dimension of behavior was 4.13 and with an overall high degree, and a total standard deviation .620. This result seems justified. One of the tasks of the faculty member is to train students in communication, dialogue and cooperation among them. And it is through its activities and procedures that enhance this type of behavior, while not neglecting ethical behaviors through guidance and direction, but the student's behavior remains his own, and a subject that is controlled by student affairs systems at the university.

In this context, Al-Khawaldeh [8] believes that the role of the faculty member is to create the appropriate educational environment, which encourages students to acquire cultural values, values of respect and democracy, and therefore it is the responsibility to provide students with the correct values such as values of loyalty, and affiliation promotes the principle of non-violence, deviation, and awareness and exercise of rights. This finding was consistent with the results of the Doghurty Study [11]. That showed that the behavioral interventions provided by the faculty member formed a context panel for changing cultural processes from globalization and the educational market where knowledge is a work.

Table 7. Arithmetic averages, standard deviations and ranks for the items on the dimension of behavior

\begin{tabular}{|c|c|c|c|c|c|}
\hline Item number & Behavior & $\mathbf{M}$ & SD & Rank & Relative importance \\
\hline 1 & $\begin{array}{l}\text { The faculty member considers that western } \\
\text { behavior is the best in life }\end{array}$ & .750 & 4.14 & 6 & High \\
\hline 2 & $\begin{array}{l}\text { A faculty member uses foreign phrases such as } \\
\text { greetings and self-identification }\end{array}$ & .796 & 4.16 & 5 & High \\
\hline 3 & $\begin{array}{l}\text { The faculty member is upset with the student's } \\
\text { opposition to the students }\end{array}$ & .936 & 3.90 & 10 & High \\
\hline 4 & $\begin{array}{l}\text { The faculty member supports holding } \\
\text { celebrations for the participation of students }\end{array}$ & .871 & 3.94 & 9 & High \\
\hline 5 & $\begin{array}{l}\text { The faculty member accepts the idea of dating } \\
\text { between students }\end{array}$ & .747 & 4.24 & 3 & High \\
\hline 6 & $\begin{array}{l}\text { The faculty member is interested in the behavior } \\
\text { of the student }\end{array}$ & .732 & 4.29 & 2 & High \\
\hline 7 & $\begin{array}{l}\text { The faculty member encourages the exchange of } \\
\text { text messages between students }\end{array}$ & .649 & 4.31 & 1 & High \\
\hline 8 & $\begin{array}{l}\text { The faculty member directs students to the } \\
\text { dangers of some websites }\end{array}$ & .740 & 4.22 & 4 & High \\
\hline 9 & $\begin{array}{l}\text { A faculty member recommends that students } \\
\text { perform plastic surgery }\end{array}$ & .773 & 4.02 & 8 & High \\
\hline \multirow[t]{2}{*}{10} & $\begin{array}{l}\text { The faculty member does not favor the student's } \\
\text { listening to foreign songs }\end{array}$ & .777 & 4.12 & 7 & High \\
\hline & Overall behavior & .620 & 4.13 & & High \\
\hline
\end{tabular}

Table 8. Arithmetic averages, standard deviations and ranks for the paragraphs of the general appearance dimension

\begin{tabular}{|c|c|c|c|c|c|}
\hline $\begin{array}{c}\text { Item } \\
\text { number }\end{array}$ & General appearance & $\mathbf{M}$ & SD & Rank & $\begin{array}{c}\text { Relative } \\
\text { importance }\end{array}$ \\
\hline 1 & $\begin{array}{l}\text { The faculty member expresses his dissatisfaction with the } \\
\text { hairdos and hairstyles }\end{array}$ & .817 & 4.31 & 4 & High \\
\hline 2 & $\begin{array}{l}\text { The faculty member directs students to wear appropriate } \\
\text { clothes at the university }\end{array}$ & .862 & 4.29 & 5 & High \\
\hline 3 & The faculty member resents from the thick beard & .705 & 4.45 & 2 & High \\
\hline 4 & $\begin{array}{l}\text { The faculty member resents those who lengthen sideburns } \\
\text { hair }\end{array}$ & 677 & 4.51 & 1 & High \\
\hline 5 & $\begin{array}{l}\text { The faculty member believes that the dress is a reflection of } \\
\text { the student's culture }\end{array}$ & .781 & 4.27 & 6 & High \\
\hline 6 & The faculty member resents and fights tattoos & .739 & 4.10 & 9 & High \\
\hline 7 & The faculty member rejects strange hair ties & .769 & 4.16 & 7 & High \\
\hline 8 & The faculty member directs us with our dress type & .792 & 4.34 & 3 & High \\
\hline 9 & $\begin{array}{l}\text { The faculty member urges me not to wear bracelets and } \\
\text { rings }\end{array}$ & .722 & 4.12 & 8 & High \\
\hline 10 & $\begin{array}{l}\text { A faculty member wearing ripped jeans is considered a } \\
\text { negative appearance }\end{array}$ & .994 & 4.04 & 10 & High \\
\hline & General Appearance & 616 & 4.30 & & High \\
\hline
\end{tabular}




\section{Third: The general appearance}

It is clear from Table (8) that all the paragraphs related to the general appearance dimension obtained a high degree through the answers of the study sample individuals, so that paragraph 4, which states: "The faculty member resents those who lengthen sideburns hair" has obtained the highest arithmetic average of 4.51 and with a high degree, paragraph No. 10 stating that: "The faculty member considers wearing ripped jeans a negative aspect" at the lowest arithmetic average, reaching 4.04 and with a high degree also, whereas, the overall arithmetic average for the overall appearance dimension was 4.30 , with a high overall score, and a total standard deviation .616. And this may be reflected in their societal behavior, and here the role of the faculty member is directive and instructive due to the nature of the prevailing laws in the Jordanian higher education system. And based on what was mentioned in the tables above, it is clear that the role of faculty members in Jordanian universities in protecting students from cultural pollution from the students' point of view was high in its three dimensions. Where the overall appearance was recorded at the highest mean average of 4.30 and a standard deviation .616, it is followed by beliefs and ideas with a mean 4.24 and a standard deviation .697, and third after behavior with an average 4.13 and a standard deviation .620 .

The second question: Are there statistically significant differences in the role of a faculty member in Jordanian universities in protecting students from cultural pollution due to variables (university, gender, specialization, school stage)?

To answer this question, the arithmetic mean, standard deviations and rank for the study sample individuals were calculated according to the variables (university, gender, academic level, and specialization), as shown in table (9).

Table 9. Arithmetic mean and standard deviations for variable dimensions (university, gender, academic level, and specialization)

\begin{tabular}{cccccc}
\hline \multirow{2}{*}{ Variable } & & M & N & Rank & SD \\
\multirow{2}{*}{ University } & Governmental & 4.19 & 1436 & 1 & .765 \\
& Private & 3.86 & 964 & 2 & .501 \\
\multirow{2}{*}{ Gender } & Male & 4.11 & 1289 & 1 & .770 \\
& Female & 4.06 & 1102 & 2 & .538 \\
\multirow{2}{*}{ Specialization } & Scientific & 4.03 & 1090 & 2 & .578 \\
& Humane & 4.14 & 1310 & 1 & .771 \\
& First & 4.21 & 717 & 1 & .799 \\
\multirow{2}{*}{ Academic level } & Second & 4.16 & 596 & 2 & .692 \\
& Third & 4.03 & 559 & 3 & .609 \\
& Fourth & 3.91 & 528 & 4 & .512 \\
\hline
\end{tabular}

It is clear from Table (9) that the category of students from the category of public universities got the highest arithmetic average of 4.19. As for the male students' category, they got the highest arithmetic average of 4.11, and the students from the humanitarian specializations category got the highest arithmetic average of 4.14 , and students from the first-year academic level obtained the highest arithmetic average of 4.21 .

And to verify the statistical significance of the differences between the arithmetic averages in the role of a teaching member in Jordanian universities in protecting students from cultural pollution among the study sample according to variables (university, gender, academic level, and specialization), multiple regression analysis was performed and the results are shown in the following table:

Table 10. Results of the differences test for the role of a faculty member in Jordanian universities in protecting students from cultural pollution according to the variables: (university, gender, academic level, and specialization)

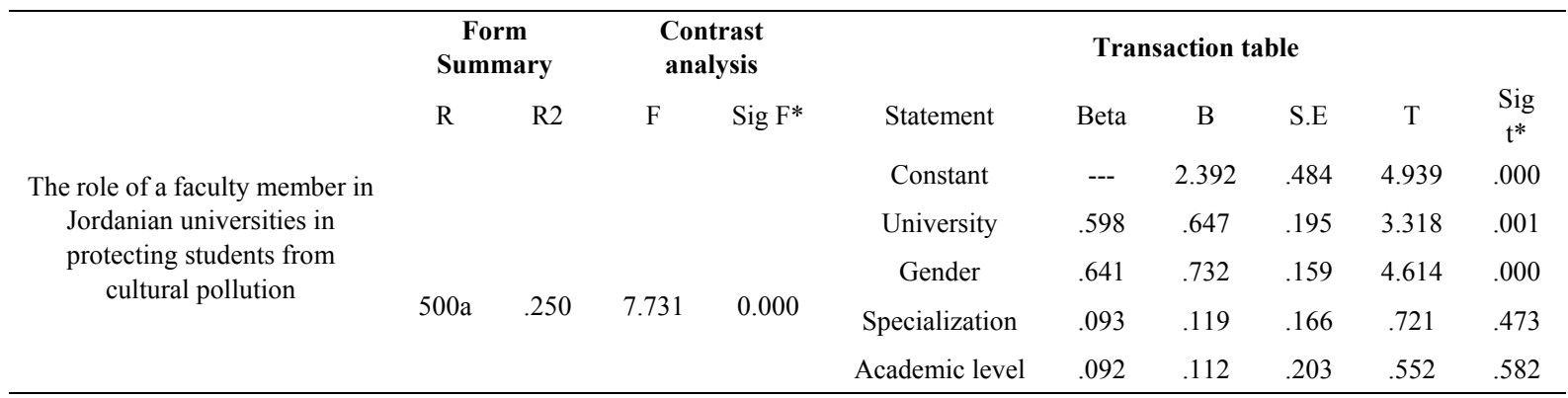

* The effect is statistically significant at the significance level $(0.05$ ( 
The results in Table (10) indicate that the correlation coefficient $\mathrm{R}=500$, and this indicates the relationship between demographic variables (university, gender, academic level, and specialization) and the role of a teaching member in Jordanian universities in protecting students from cultural pollution, and there is a statistically significant effect, where the calculated $F$ value was 7.731 and the Sig F level 0.000, which is less than 0.05 , it showed that the value of the determination coefficient $\mathrm{R}^{2}=.250$ indicates that $25 \%$ of the variation in the role of the teaching member in Jordanian universities in protecting students from cultural pollution can be explained by the variation in demographic variables: (University, gender, academic level, and specialization) combined, and that the value $75 \%$ is due to other factors not included in the study model. As for the table of transactions, it has been shown that the value of (B) at the distance of the university has reached .598 and that the value of $(\mathrm{T})$ at it has reached 3.318 and at the level of significance .001 , which indicates that the effect of this variable is significant, and accordingly there are statistically significant differences in the teaching member in Jordanian universities in protecting students from cultural pollution due to the university variable and for the benefit of public universities. And that the value of (B) at the dimension of sex has reached .641 and that the value of $(\mathrm{T})$ has 4.614 and at the level of significance .000 , accordingly, there are statistically significant differences in the teaching member of Jordanian universities in protecting students from cultural pollution due to the gender variable and in favor of males.

This result seems justified, as the male faculty members are more able to interact with their students and talk to them. And confronting them with the facts of cultural pollution or the intellectual and behavioral drift that most women suffer from, this, of course, does not neglect their role in dealing with female students, but the matter remains that cultural pollution affects students more than it affects female students and therefore there is a need to educate them and protect them more. This is consistent with what Al-Obeidi study [14] showed, that cultural pollution affects males more than females in universities.

While the results showed that the value of (B) at specialization has reached .093 and that the value of (T) at it has reached .721 at the level of significance .473 , which indicates that the effect of this variable is not significant, that the value of (B) at the dimension of the academic level has reached .092 and that the value of $(\mathrm{T})$ at it has reached .552 and the level of significance .582 , which indicates that the effect of this variable is not significant, and accordingly there are no statistically significant differences in the role of the teaching member in Jordanian universities in protecting students from cultural pollution due to the variables of specialization and the academic level.

This means that all faculty members are academically and ethically concerned with facing cultural pollution among their students, as the student often suffers from a clear ignorance of the issues and variables of the times, and from a clearer intellectual emptiness to the predominance of indoctrination, arrogance, and the absence of a language of dialogue, and the curriculum is devoid of authentic cultural thought, so selecting a faculty member, regardless of his position at the university, or the student's specialization or academic level concerned with providing the student's immunity, guidance. This is consistent with what was reported by [1], that satellite channels use indirect means, including films and series that include the arts and methods of persuasion that are presented in bright and attractive templates. Where they arrive indirectly, and may therefore affect changing attitudes, ideas and beliefs, and therefore the educational institution must provide immunity to the student in order to protect him from cultural pollution.

\section{Recommendations}

1. Activating the role of faculty members in the prevention of cultural pollution through more training and specialized workshops.

2. Delegating disciplinary and follow-up powers to a faculty member so that he/she can exercise his/her preventive and curative role.

3. Educating male and female students about the importance of the role of the faculty member in protecting them from cultural pollution.

4. Conducting comparative studies on cultural pollution with other societal segments and comparing them with the results of the current study.

\section{Acknowledgments}

The authors would like to thank the Deanship of Scientific Research of Al-Balqa Applied University for Funding.

\section{REFERENCES}

[1] Sukran, M. Education and cultural pollution. A critical analytical view. Journal of the Association of Modern Education. 2016; 8 (27), 15-27.

[2] Liu, Y. An Analysis of Promoting Mental Health Education of the University Students. Asian Social Science. 2010; 6(7), 118- 122 .

[3] Mahmoud, D., Rahem, N. \& Talib, H. Cultural pollution among students of the College of Education for Girls. Al-Ustaz Journal. 2016; 2 (217), 115-128.

[4] Salim, M. Developmental psychology. Beirut: Arab Renaissance House for Distribution, Printing and Publishing. 2002. 
[5] Guo, Y. Discussing the Mental Health Education of the University Students. Journal of Langfang Normal College. 2007; 23 (01) 107- 108.

[6] Hudson, A. Globalization and universities in the Commonwealth Caribbean. New York, Rowman and Little Field. 2004.

[7] Nalder, G. The Art of "Globalization، the Culture of difference, the Industry of knowledge age". 1999; Eric No: Ed 455154

[8] Al-Khawaldeh, T. The role of a faculty member in Jordanian universities in developing the values of citizenship from the students' point of view. Dirasat: Educational Sciences. 2013; 40 (3), 1160-1180.

[9] Abu Daf, M. \& Al-Agha, M. Cultural pollution among youth in Palestinian society and the role of education in confronting it. Journal of the Islamic University. 2001; 9 (2), 58-108.

[10] Yeh, C., Carter, R. \& Pieterse, A. Cultural Values and Racial Identity Attitudes among Asian American Students: An Exploratory Investigation. Counseling and Values. 2004; 8 (2), 82-95.

[11] Doghurty, E. Cultural Similarity and Differences. Journal of Education. 2006; 3(3), 22-56.

[12] Geozek, D. The Role of Faculty member in cultural Transmission. Asian Social Science. 2009; 4 (2) ، 222- 278.

[13] Lam, T. The Impact of Vietnam's Globalization on National Education Policies and Teacher Training Programs for teachers. DAI 2011; 27(09), 2151.

[14] Al-Obaidi, A. Cultural pollution and its relationship to the family climate among a sample of university students. Journal of Human and Society Sciences. 2013; 6 (7), 75-101.
[15] Qaisi, 1. University youth problems at Tafila Technical University. Al-Quds Open University Journal for Research and Studies. 2014; 2 (6), 365-392.

[16] Arhuma, k. The role of cultural channels in changing some cultural habits of Libyan youth. Libyan Journal of Studies, Libya. 2014; 6 (6), 259-282.

[17] Shepherd, Stephane M., et al. "The impact of indigenous cultural identity and cultural engagement on violent offending." BMC public health 18.1 (2018): 1-7.

[18] Weber, Silvana, Nicole Kronberger, and Markus Appel. "Immigrant students' educational trajectories: The influence of cultural identity and stereotype threat." Self and Identity 17.2 (2018): 211-235.

[19] Mironenko, Irina A., and Pavel S. Sorokin. "Seeking for the Definition of "Culture": Current Concerns and their Implications. A Comment on Gustav Jahoda's Article "Critical Reflections on some Recent Definitions of "Culture"." Integrative Psychological and Behavioral Science 52.2 (2018): 331-340.

[20] Myers, James T. "Socialist spiritual civilization and cultural pollution: The problem of meaning." Mainland China. Routledge, 2019. 277-328.

[21] Douglas, Kate, and Anna Poletti. Life Narratives and Youth Culture: Representation, Agency and Participation. Springer, 2016.

[22] Poyntz, Stuart R., and Jennesia Pedri. "Youth and Media Culture." Oxford Research Encyclopedia of Education. 2018.

[23] Bansal, Parul. "Unit-5 Youth Culture: Influence of media and globalization." Indira Gandhi National Open University, New Delhi, 2020. 